\title{
FORMAS, PROCESSOS E PADRÕES NA EROSÃO POR RAVINAMENTO: PARA UM ENQUADRAMENTO TEÓRICO COERENTE
}

\author{
RAFAELLO BERGONSE ${ }^{1}$ \\ EUSÉBIO REIS ${ }^{1}$
}

\begin{abstract}
Resumo - Apesar de um vasto corpo de literatura, não há um enquadramento teórico coerente sobre a erosão por ravinamento. A sua variabilidade morfológica e processual não é compatível com as definições de ravina na literatura, nem com a noção prevalecente do ravinamento como um processo hídrico cujas fronteiras são arbitrariamente definidas entre canais de menor e maior dimensão. Esta discrepância condiciona inevitavelmente as abordagens metodológicas de que o fenómeno é alvo, e portanto a objectividade dos resultados obtidos. O presente artigo assenta numa revisão extensa da literatura, com o fim de estabelecer uma comparação crítica entre as formas, processos e padrões de desenvolvimento descritos e o enquadramento conceptual dominante, e definir questões prioritárias de investigação. Adicionalmente, é realizada uma revisão dos estudos dedicados em Portugal, até ao momento, a este processo morfogenético.
\end{abstract} mórfico.

Palavras-chave: Ravinamento, erosão hídrica, movimentos de massa, limiar geo-

\begin{abstract}
FORMS, PROCESSES AND PATTERNS IN GULLY EROSION: TOWARD A COHERENT THEORETICAL FRAMEWORK. In spite of a vast body of literature, gully erosion does not yet possess a coherent theoretical framework. Its variability, both in terms of process and morphology, is incompatible both with the current definitions of gully, and with the prevalent notion of these forms as a product of concentrated flow whose boundaries are arbitrarily defined between smaller and larger channels. This contrast inevitably constrains methodological approaches to the phenomenon, as well as their results. The present paper draws on an extensive review of the literature with the purposes of establishing a critical comparison between the forms, processes and development patterns described and the prevailing conceptual framework, as well as on the definitions of relevant research questions. Additionally, a review is made of gully erosion studies in Portugal to this date.
\end{abstract}

Keywords: Gully erosion, water erosion, mass movements, geomorphic threshold.

Recebido: Março 2011. Aceite: Novembro 2011.

1 Centro de Estudos Geográficos da Universidade de Lisboa. E-Mail: rafaellobergonse@gmail. com; eusebioreis@campus.ul.pt 
Résumé - FORMES, PROCESSUS ET MODELES D'EROSION PAR RAVINEMENT : VERS UN ENCADREMENT THÉORIQUE COHÉRENT. L'érosion par ravinement ne possède pas d'encadrement théorique cohérent, et ce malgré le fait qu'elle ait bénéficié de nombreux travaux de recherche. La variabilité de son processus et de sa morphologie n'est pas compatible avec les définitions de ravin présentes dans la littérature, ni avec la notion prépondérante du ravinement comme étant un processus hydrique dont les frontières sont arbitrairement définies entre des canaux de petites et de grandes dimensions. Cette divergence conditionne inévitablement les approches méthodologiques dont le phénomène est l'objet, et ainsi l'objectivité des résultats obtenus. Le présent article est basé sur une révision étendue de la littérature afin d'établir une comparaison critique entre les formes, les processus et les modèles de développement décrits et l'encadrement conceptuel dominant. De plus, cela a permis de définir des axes de recherche prioritaires. Enfin, on a réalisé une révision des études qui ont été dédiées à ce processus morphogénétique au Portugal.

Mots clés: Ravinement, érosion hydrique, mouvements de masse, seuil géomorphique.

\section{INTRODUÇÃO}

A formação de ravinas tem sido descrita numa enorme variedade de paisagens e condições climáticas (Poesen et al., 2003). Apesar das dificuldades inerentes ao seu estudo e modelação e ao conhecimento da sua importância relativamente a outros tipos de erosão hídrica habitualmente individualizados (i.e. laminar ou inter-sulcos, em sulcos e tubulação, cf. Bryan, 2000; Boardman e Poesen, 2006), a análise da literatura permite observar que o ravinamento é frequentemente o processo erosivo predominante (Poesen et al., 1996; Wasson et al., 2002), podendo gerar taxas de erosão muito variáveis, e.g. 1,6 ton/ha/ano (Valcárcel et al., 2003) ou $576 \pm 58$ ton/ha/ano (Martínez-Casanovas et al., 2003).

Apesar dos muitos trabalhos de que tem sido alvo, o fenómeno encontra-se enquadrado teoricamente de forma contraditória, de que são exemplo as numerosas definições de ravina publicadas e os diferentes pressupostos que lhes estão associados. Ao mesmo tempo, a inclusão do ravinamento na classe dos processos de erosão hídrica é baseada numa perspectiva parcial, centrada na ocorrência de ravinas incipientes em solo agrícola em desfavor de formas desenvolvidas, com cujas propriedades e dinâmica não é frequentemente compatível. A prevalência desta visão parcial condiciona as abordagens metodológicas a que o fenómeno é sujeito e, naturalmente, o conhecimento resultante, com consequências práticas na frequente inadequação das medidas de prevenção e controlo aplicadas.

No presente estudo é realizada uma revisão da literatura no que concerne às definições de ravina e ravinamento, sendo depois considerados os contextos espaciais da sua ocorrência, processos de formação e evolução, e padrões de desenvolvimento ao longo do tempo. Os resultados são depois sujeitos a uma comparação crítica com o fim de propor um enquadramento conceptual coerente, de acordo com o qual é definido um conjunto de questões de investigação prioritárias. Por fim, é realizada uma revisão dos estudos dedicados ao fenómeno em Portugal. 


\section{OS CONCEITOS DE RAVINA E DE RAVINAMENTO}

Diferentes autores propõem que há um continuum entre canais resultantes de erosão hídrica (sulcos, ravinas e canais fluviais), e que qualquer diferenciação em classes será, em certa medida, subjectiva (Grissinger, 1996; Poesen et al. 2003, 2006). Esta subjectividade está patente nas próprias definições de ravina presentes na literatura (Quadro 1). Os exemplos apresentados mostram que se por um lado as várias definições associam a forma à acção erosiva do escoamento concentrado, por outro cada uma lhe atribui diferentes propriedades, desde o comportamento hidrológico à morfologia, à posição topográfica, ou à relação com as actividades humanas.

Quadro I. Definições de "ravina" na literatura.

Table I. Published definitions of gully.

\begin{tabular}{|c|c|}
\hline Definições de ravina & Autores \\
\hline $\begin{array}{l}\text { "canal de drenagem cuja largura e profundidade não permitem uma lavoura } \\
\text { normal" }\end{array}$ & FAO $(1965)^{1}$ \\
\hline $\begin{array}{l}\text { "um canal de drenagem efémero entalhado em depósitos sedimentares espessos } \\
\text { ou rocha mãe" }\end{array}$ & $\begin{array}{l}\text { Gregory e Walling } \\
\qquad(1973)^{2}\end{array}$ \\
\hline $\begin{array}{l}\text { "um canal originado pelo escoamento concentrado, com uma profundidade mí- } \\
\text { nima de } 0,3 \mathrm{~m} \text {, e que resulta na fragmentação da vertente" }\end{array}$ & Zachar (1982) \\
\hline $\begin{array}{l}\text { "um canal relativamente fundo, instável e em processo de erosão, que se forma } \\
\text { na cabeceira, lados ou fundo de um vale onde nenhum canal bem definido exis- } \\
\text { tia previamente" }\end{array}$ & Schumm et al. $(1984)^{3}$ \\
\hline $\begin{array}{l}\text { "um canal resultante de incisão fluvial em materiais não consolidados, caracte- } \\
\text { rizado por transmissão efémera de escoamento, lados declivosos, e cabeceira } \\
\text { fortemente declivosa ou vertical" }\end{array}$ & Ebisemiju e Ekiti (1989) \\
\hline $\begin{array}{l}\text { "um canal geralmente permanente, de secção em V e paredes laterais com um } \\
\text { declive próximo do ângulo de estabilidade dos sedimentos não consolidados" }\end{array}$ & $\begin{array}{l}\text { Bull e Kirkby } \\
\text { (1997) }\end{array}$ \\
\hline $\begin{array}{l}\text { "um canal erodido pelo fluxo concentrado mas intermitente de água, [que tem } \\
\text { lugar] habitualmente durante e imediatamente após a ocorrência de chuvas } \\
\text { intensas, sendo profundo o suficiente para interferir com a lavoura normal e não } \\
\text { ser por ela eliminado" }\end{array}$ & $\begin{array}{l}\text { Soil Science Society } \\
\text { of America (2001) }\end{array}$ \\
\hline $\begin{array}{l}\text { "um canal de drenagem relativamente permanente, de paredes declivosas, e que } \\
\text { regista escoamento efémero em contextos de alimentação em precipitação" }\end{array}$ & Morgan (2005) \\
\hline $\begin{array}{l}\text { "uma incisão ao longo de uma linha de drenagem que apresenta sinais claros de } \\
\text { degradação, com uma cabeceira constituindo uma quebra bem definida no de- } \\
\text { clive" }\end{array}$ & $\begin{array}{l}\text { Hancock e Evans } \\
\text { (2006) }\end{array}$ \\
\hline $\begin{array}{l}\text { "um canal profundo numa vertente, geralmente entalhado pelo escoamento, e } \\
\text { frequentemente sem fluxo permanente" }\end{array}$ & $\begin{array}{l}\text { Kirkby e Bracken } \\
(2009)\end{array}$ \\
\hline $\begin{array}{l}{ }^{1} \text { Cit. por Bocco (1991) } \\
{ }^{2} \text { Cit.por Burkard e Kostachuk (1997) } \\
{ }^{3} \text { Cit. por De Rose et al. (1998) }\end{array}$ & \\
\hline
\end{tabular}

Tal como a sua definição, a distinção entre estas formas e outros entalhes menores (sulcos) foi alvo de diferentes propostas, na sua maioria assentes em critérios morfométricos. Brice (1966), cit. por Poesen et al. (2003) propôs uma largura mínima de $0,3 \mathrm{~m}$ e uma profundidade mínima de 0,6 m. Imeson e Kwaad (1980) definiram uma profundidade mínima de 
0,5 m. Zachar (1982) preferiu os 0,3 m, e Hauge (1977) e depois Poesen (1993) uma área de secção crítica de $929 \mathrm{~cm}^{2}$ (um pé quadrado). Outro critério já proposto é a posição face à macrotopografia, assente numa pressuposta tendência das ravinas para ressurgirem no mesmo local após a sua eliminação (Grissinger, 1996; Toy et al., 2002). Por oposição ao seu limite inferior, o limite superior não foi ainda alvo de definição (Poesen et al. 2003). Este facto resultará, pelo menos em parte, da posição algo ambivalente deste processo erosivo enquanto tema de investigação. Com efeito, embora se trate de um fenómeno morfogenético, é também um processo de erosão do solo, e portanto sujeito a uma abordagem centrada na aplicação prática. É neste contexto que o surgimento de canais adquire muito maior relevância, pela frequência com que afecta solos agricultados, do que a sua evolução ao longo de décadas ou séculos, frequentemente em áreas (presentemente) marginais para a agricultura (e.g. Boardman et al. 2003).

Em contraste com as muitas definições para as formas estudadas, a revisão da literatura permitiu encontrar uma única definição para o processo subjacente (Soil Science Society of America, 2001; Poesen et al., 2006). O ravinamento é definido como:

"o processo erosivo pelo qual o escoamento se acumula em canais estreitos, de forma frequentemente recorrente e, em períodos curtos, remove o solo desta área estreita até profundidades consideráveis".

\section{TIPOS E CONTEXTOS ESPACIAIS DO RAVINAMENTO}

A variabilidade nas formas estudadas em diferentes locais tem motivado a definição de tipologias por diferentes autores. Algumas destas classificações assentam em critérios múltiplos, tendo sido concebidas para contextos geográficos específicos (e.g. forma da secção transversal, quantidade de cabeceiras e processos de evolução na Tunísia, cf. De Ploey, 1974). Outras são essencialmente morfométricas, levando em conta a profundidade e a forma da secção transversal (Zachar, 1982) ou a geometria hidráulica (Billy e Dramis, 2003). Outras ainda assentam em padrões evolutivos. Neste contexto, Leopold et al. (1964) desenvolveram a noção de ravinas descontínuas e contínuas, pressupondo duas fases sucessivas de desenvolvimento, em que entalhes inicialmente descontínuos ao longo de uma depressão topográfica evoluem para formar um só canal contínuo.

A análise da literatura torna claro que o critério mais amplamente utilizado para estabelecer uma diferenciação básica entre ravinas é o condicionamento imposto às actividades agrícolas (Toy et al., 2002; Poesen et al., 2003; 2006). Assim, definem-se ravinas efémeras como "pequenos canais entalhados pelo escoamento concentrado que podem ser facilmente eliminados pela lavoura normal (normal tillage no original), para reaparecerem no mesmo local em função de episódios posteriores de escoamento" (Soil Science Society of America, 2001). Por oposição, as ravinas permanentes, também denominadas clássicas, correspondem a "canais profundos demais para poderem ser facilmente eliminados com recurso a material de lavoura comum, com profundidades que variam tipicamente entre os $0,5 \mathrm{~m}$ e os 25 a 30 m" (op.cit.) ${ }^{2}$. Apesar da ampla aceitação, sem dúvida promovida pela sua utilidade

2 Esta diferenciação foi introduzida no início dos anos 1980 nos Estados Unidos da América para permitir incluir nas avaliações de erosão do solo as perdas resultantes do escoamento em canais de dimensões intermédias entre os sulcos (efémeros e sem tendência a ressurgir no mesmo local) e as ravinas de dimensões mais significativas. 
prática, este critério faz com que o limiar de dimensão entre formas efémeras e permanentes varie no espaço e no tempo de acordo com as variações na tecnologia disponível (Nachtergaele et al., 2002a) e torna a classificação incompatível com outros usos (e.g. florestal, pastagem), onde qualquer ravina será permanente desde o surgimento (Wainwright e Thornes, 2004).

A dicotomia permanente/efémera tem estado na base da individualização de dois grandes sub-temas nos estudos do ravinamento: por um lado, o surgimento e a dinâmica de ravinas (efémeras), habitualmente em campos agrícolas, e o conjunto de mecanismos e factores associados, normalmente em escalas temporais relativamente curtas como episódios de precipitação, dias ou meses (Vandaele et al., 1996; Vandekerkhove et al., 1998, 2000a; Woodward, 1999; Nachtergaele et al., 2001; Souchére et al., 2003; Capra et al., 2005). Por outro lado, as características e dinâmicas temporais de formas permanentemente entalhadas, em escalas que vão dos poucos anos até vários milénios (Boardman et al., 2003; Gábris et al., 2003; Vandekerckhove et al., 2003; Panin et al., 2009).

Optou-se no presente trabalho por diferenciar tipologias de ravina em função do contexto topográfico em que se inserem (Fig.1). A topografia, ao influenciar de forma determinante a quantidade de escoamento (superficial e sub-superficial) disponível para produzir efeitos geomórficos, a sua velocidade (i.e. erosividade), e as tensões a que o rególito é sujeito (e portanto a ocorrência de movimentos de massa) permite estabelecer um nível elementar de diferenciação, condicionando não só os contextos espaciais em que estas formas se iniciam, mas também dinâmicas evolutivas particulares.

As noções de ravina de fundo e de vertente foram inicialmente propostas por Ireland et al. (1939), cit. por Bocco (1991). As primeiras (valley-bottom gullies) caracterizam-se por uma concentração do escoamento topograficamente definida (i.e. fundos de vale e concavidades transversais em vertentes). Incluídos nesta classe estão os arroyos característicos do Oeste dos E.U.A., localizados tipicamente em fundos de vale relativamente planos (Goudie, 2004).

As ravinas de vertente (valley-side gullies) também denominadas ravinas de meia-vertente $^{3}$ (Harvey e Gutiérrez-Elorza, 2005) formam-se onde o escoamento se concentra localmente, por exemplo em áreas sobrepastoreadas, sulcos resultantes da lavra, limites de propriedades ou caminhos de gado (e.g. Morgan e Mngomezulu, 2003). A concentração do fluxo não é determinada pela macro-topografia, mas pela presença de perturbações na forma da superfície ou por um aumento da erodibilidade do rególito.

Por fim, as ravinas de desnível (bank gullies) caracterizam-se pela pré-existência de uma quebra no declive, associada a um aumento da velocidade e do poder erosivo do escoamento superficial e potencialmente à concentração e acção erosiva do escoamento sub-superficial, bem como à ocorrência de movimentos de massa. $\mathrm{O}$ colapso de vias preferenciais de escoamento sub-superficial (i.e. tubos) é frequentemente o evento iniciador de uma nova ravina deste tipo (vd. Fig.1, C, D e E). São exemplos de desníveis as margens de cursos de água (Vandekerckhove et al., 2000b), os terraços abandonados (Lesschen et al., 2008), e as paredes de ravinas pré-existentes (Desir et al., 2009) e de canais de drenagem artificiais (Casalí et al., 1999b). Este tipo engloba o que Harvey e Gutiérrez-Elorza (2005) denominam "ravinas de indução basal" (basally induced gullies).

3 Midslope gullies no original. Optou-se por não utilizar esta designação, já que refere especificamente uma posição relativa na vertente que pode não se verificar. 


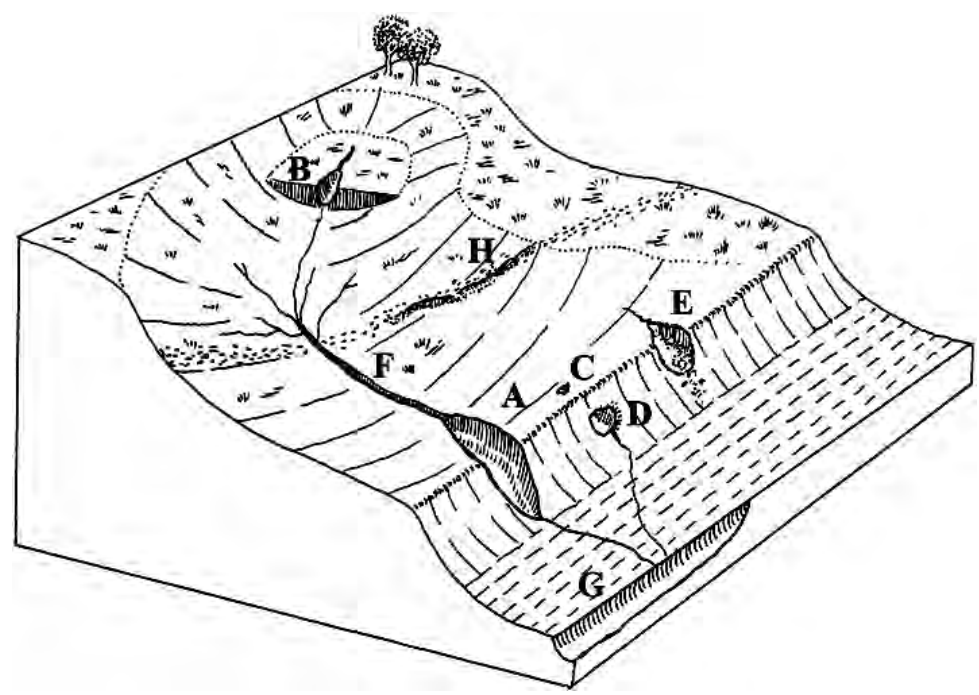

Fig.1 - Contextos topográficos do surgimento de ravinas. A- Ravina de desnível em margem de curso de água; B- ravina de desnível em terraço; C- entrada de tubo (pipe); D- desembocadura de tubo; E- ravina de desnível recém formada pelo colapso de um tubo. F- ravina de fundo; G- Ravina de fundo do tipo arroyo; H- Ravina de vertente associada a um trilho de gado.

Adaptado de Wainwright e Thornes (2004: 179) e Poesen et al. (1996: 252; 2006: 517).

Fig. 1 - Topographical contexts of gully formation. A-Bank gully in the margin of a watercourse; $\boldsymbol{B}$ - Bank gully in a terrace; $\boldsymbol{C}$-Pipe inlet; $\boldsymbol{D}$-Pipe outlet; $\boldsymbol{E}$ - Bank gully recently originated by pipe collapse; $\boldsymbol{F}$-Valley-bottom gully; $\boldsymbol{G}$-Valley-bottom gully of the arroyo type; $\boldsymbol{H}$-Hillslope gully associated with cattle trail.

Adapted from Wainwright and Thornes (2004) and Poesen et al. (1996; 2006).

\section{MECANISMOS E PROCESSOS DE SURGIMENTO E EVOLUÇÃO}

Em cada um dos contextos topográficos acima enumerados, a formação e a evolução de ravinas ocorre através de três diferentes mecanismos: (1) surgimento e posterior aprofundamento e extensão para jusante de um entalhe; (2) recuo da cabeceira para montante, (3) alargamento do canal. Por sua vez, estes mecanismos são movidos directamente por dois processos: o escoamento superficial concentrado e os movimentos de massa. Cada um será considerado em separado.

\section{O escoamento superficial concentrado}

A acção do escoamento concentrado, agindo fundamentalmente sobre a cabeceira e o fundo dos canais, assenta na oposição dinâmica entre a sua erosividade (i.e. a capacidade

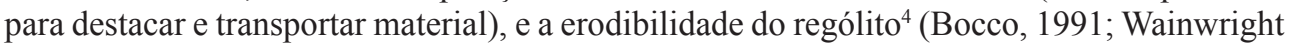

4 Optou-se por rególito em vez de solo, já que o material onde o escoamento tem lugar não possui necessariamente os atributos de um solo propriamente dito, designadamente a capacidade para sustentar crescimento vegetal. 
e Thornes, 2004). A acção erosiva do escoamento, tanto laminar como concentrado, constitui adicionalmente um factor de alargamento das paredes de ravinas (e.g. Crouch e Blong, 1989; Vandekerckhove et al., 2000b). No entanto, o total predomínio dos movimentos de massa neste contexto faz com que lhe seja habitualmente dada pouca importância.

A erosividade do escoamento é controlada essencialmente pela velocidade do fluxo, por sua vez função da sua profundidade, do declive e da geometria do canal (no caso de o escoamento ser concentrado), e da rugosidade do leito. Estes parâmetros podem ser combinados em numerosos indicadores compostos, dos quais são exemplos a tensão tangencial (shear stress, $\tau)^{5}$ (Poesen et al., 2003), a velocidade tangencial (shear velocity, $\left.u_{*}\right)^{6}$ (Rauws e Govers, 1988) ou a potência de escoamento (stream power, $\omega)^{7}$ (Nearing et al., 1997).

A capacidade do escoamento para destacar sedimentos num dado momento é condicionada pela quantidade de material já transportada (Toy et al., 2002). Foster et al. (1995) representaram esta relação com a formulação:

$$
D f=D_{c}\left(1-\frac{q s}{T_{c}}\right)
$$

em que $D f$ é a taxa de destacamento em $K g \cdot m^{-2} \cdot s^{-1}, D_{c}$ é a capacidade de destacamento de sedimentos do fluxo $\left(K g \cdot \mathrm{m}^{-2} \cdot \mathrm{s}^{-1}\right)$ e $q s$ e $T_{c}$ são a carga de sedimentos transportada e a capacidade de transporte, ambas em $K g \cdot m^{-1} \cdot s^{-1}$. É assumida uma relação linear entre os dois casos extremos em que não há sedimento na água $\left(q s / T_{c}=0\right)$ e em que esta já atingiu a capacidade de transporte $\left(q s / T_{c}=1\right)$, sendo a taxa de destacamento nula neste caso.

Apesar da variedade de indicadores de erosividade, não existe consenso na literatura quanto à relação exacta entre destacamento e transporte ou quanto ao melhor indicador para descrever estes dois processos (Govers et al., 2007).

A canalização do escoamento ocorre quando a resistência do rególito é ultrapassada pela erosividade do fluxo. Dada a complexidade inerente à geração do escoamento numa vertente, o surgimento de ravinas tem sido frequentemente alvo de uma abordagem empírica, de acordo com a noção proposta inicialmente por Horton (1945, cit. por Leopold et al., 1964) de um limiar a partir do qual a força erosiva da água é superior à resistência oposta, definindo numa vertente o início da área onde existem condições para o entalhe. Este é o princípio em que se baseiam numerosos trabalhos que pretendem prever a localização de ravinas efémeras com recurso a limiares topográficos, frequentemente do tipo,

$$
S_{c r}=a A^{-b}
$$

em que $S_{c r}$ é o declive crítico (m/m), $A$ é a área de drenagem (ha), $a$ é um coeficiente e $b$ um expoente (Desmet et al., 1999; Zucca et al., 2006; Kakembo et al., 2009). Casalí et al. (1999a) e De Santisteban et al. (2005) utilizaram o declive e a área de drenagem para estabelecer índices de susceptibilidade à formação de ravinas em diferentes bacias.

A erodibilidade do solo, i.e. a sua capacidade para opor resistência à erosividade do escoamento, é uma propriedade complexa, sendo controlada por numerosos factores, funcionando a diferentes escalas espaciais e temporais. São exemplos a textura, a agregação, a coerência entre os agregados, o conteúdo em água, o efeito das raízes das plantas, o conteúdo

$5 \tau=\rho g R S$, em que $\rho$ é a densidade da água $\left(\mathrm{g} . \mathrm{cm}^{-3}\right), g$ é a aceleração devida à gravidade $\left(\mathrm{cm} . \mathrm{s}^{-2}\right)$, $R$ é o raio hidráulico, e $S$ é o seno do ângulo de inclinação da superfície da água. $\tau$ é expressa em Pa.

$u_{*}=\sqrt{g R s}$. É expressa em cm.s.

$\omega=\tau V$, em que $\mathrm{V}$ é a velocidade do escoamento $\left(\mathrm{m} \cdot \mathrm{s}^{-1}\right)$. 
em fragmentos de rocha, a densidade aparente ou a dispersividade da fracção argilosa, conduzindo esta última ao encrostamento do solo em contextos de precipitação. Estas variáveis interagem frequentemente entre si e afectam em simultâneo a erosividade do escoamento (e.g. fragmentos superficiais de rocha diminuem a erodibilidade e ao mesmo tempo reduzem a erosividade; encrostamento reduz a erodibilidade mas aumenta a erosividade). Foram alvo de revisões por Bryan (2000) e Knapen et al. (2007) e, dadas as limitações de formato, não serão aqui consideradas.

\section{Movimentos de massa}

Os movimentos de massa relacionam-se com o ravinamento em três contextos: $(i)$ o surgimento de novas ravinas em locais previamente não entalhados, e.g. vertentes (Alexander, 1982; Menendez-Duarte et al. 2007) ou terraços (Harvey, 1982); (ii) o seu surgimento através da bifurcação de canais pré-existentes, incluindo outras ravinas; (iii) a expansão de ravinas. A sua acção no surgimento de novas formas é necessariamente indirecta, na medida em que, por definição, só existe um canal devido à acção do escoamento, mesmo que o colapso e a acção de entalhe tenham lugar quase em simultâneo (i.e. durante um episódio chuvoso). Por oposição, existe uma acção directa dos movimentos de massa na expansão de ravinas pré-existentes, quer esta se articule ou não com a acção do escoamento para originar uma bifurcação.

A ocorrência de movimentos de massa nas cabeceiras e paredes de ravinas é controlada pela dinâmica entre a resistência da massa de material e as tensões sobre ela exercidas. Estas duas grandezas resultam da conjugação de numerosos factores, designadamente a altura do canal, o declive da parede/cabeceira e as suas propriedades físicas, bem como a variação destas últimas ao longo do seu perfil (e.g. permeabilidade de diferentes horizontes do solo), e ao longo do tempo (e.g. instabilização causada pelas variações de volume da água no rególito durante ciclos de congelamento/fusão, cf. Thomas et al., 2009). Adicionalmente, a massa dos elementos exteriores ao próprio rególito (e.g. árvores) contribui para o aumento da tensão.

Podem individualizar-se seis sub-processos activos na ocorrência de movimentos de massa em ravinas:

(1) sapamento basal nas paredes e cabeceiras em função da libertação das tensões exercidas pelo próprio peso do material, e ao afloramento da drenagem sub-superficial (e.g. Bradford e Piest, 1980). Estas sapas são tradicionalmente designadas seepage hollows na literatura em língua inglesa.

(2) sapamento basal nas paredes resultante da acção erosiva do escoamento no fundo da ravina.

(3) formação e alargamento de tubos, frequentemente em materiais dispersivos, afectando tanto a cabeceira como as paredes (e.g. Seeger et al., 2009).

(4) sapamento basal da cabeceira, directamente resultante do impacto vertical do escoamento (e.g. Oostwoud Wijdenes et al., 2000). A forma deprimida originada na base da cabeceira é denominada plunge-pool, o que pode ser traduzido como "bacia de impacto".

(5) formação e colapso de caneluras desenvolvidas na cabeceira e nas paredes em função do escoamento superficial, sub-superficial e do impacto da precipitação. Este processo é denominado fluting (e.g. Crouch e Blong, 1989; Brooks et al., 2009).

(6) formação de fracturas, tipicamente umas dezenas de centímetros a montante dos limites superiores das paredes e da cabeceira, associadas à libertação da tensão originada pelo desnível sobre a massa de material, e possivelmente por tensões 
associadas a ciclos de humedecimento/secagem do solo (Collison, 2001; Oostwoud Wijdenes e Bryan, 2001). Estas descontinuidades diminuem o comprimento do potencial plano de ruptura, favorecem a infiltração, e podem originar pressões intersticiais positivas quando são preenchidas por água, contribuindo para a instabilidade (Bull e Kirkby, 1997). A sua ocorrência é promovida pelas formas de sapamento basal referidas em (1), (2) e (4).

Estes sub-processos combinam-se de diferentes formas para remover material da cabeceira e das paredes de ravinas, sendo estes movimentos de massa fortemente influenciados pelas condições hidrológicas do material, determinantes da sua coesão aparente e da tensão a que é sujeito por acção da gravidade. Bocco (1991) propõe que a importância das condições hidrológicas nos processos de ravinamento torna relevante considerar a humidade antecedente e a quantidade de precipitação como variáveis climáticas críticas, para além da sua intensidade (associada à geração de escoamento superficial erosivo).

Bull e Kirkby (1997) referem que, num contexto em que as fracturas de tensão ocupem uma parte significativa da altura das paredes, a evolução pode ocorrer por balançamento (toppling) de porções da parede, sendo neste caso a força tênsil do rególito o factor crítico. Bradford e Piest (1980) descreveram um processo semelhante na evolução das cabeceiras em ravinas de fundo (que denominaram slab failure), salientando adicionalmente a força compressiva do solo sob a porção da cabeceira destacada pelas fracturas de tensão: o balançamento terá lugar quando a massa desta última ultrapassa a força do solo.

O balançamento também é associado por Collison (2001) à acção conjunta de fracturação e sapamento intensos, podendo ocorrer sem que se dê saturação do solo com água. Este autor propôs um processo cíclico de recuo de cabeceiras assente na combinação entre fracturas de tensão, sapamento basal e escoamento sub-superficial, e também aplicável às paredes de canais (fig. 2). Após uma primeira fase, em que a libertação de tensões resultante da incisão (a) origina as fracturas e a sapa (b), a infiltração é promovida pelas primeiras, originando uma aceleração do escoamento sub-superficial (c), cujo afloramento se dá na base da cabeceira, dinamizando o sapamento e potencialmente a tubulação. Em condições de precipitação suficiente, as pressões intersticiais positivas resultantes do preenchimento das fracturas com água reduzirão a resistência do material ao ponto de provocar o colapso, ao longo de um plano de ruptura tangencial definido entre as fracturas e a sapa basal (d). Escoamento posterior no canal remove o material depositado, possibilitando o recomeçar do ciclo.

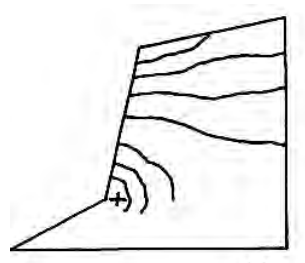

(a)

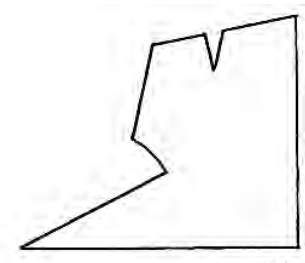

(b)

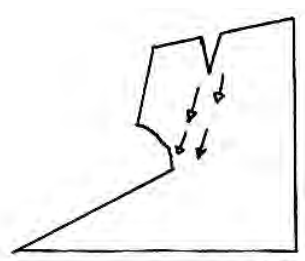

(c)

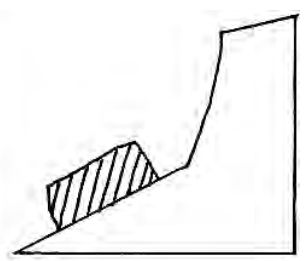

(d)

Fig. 2 - Ciclo hipotético de recuo de cabeceiras proposto por Collison (2001). As linhas contínuas em (a) representam planos de igual tensão tangencial no perfil da cabeceira, sendo o máximo $(+)$ atingido junto à base (adaptado de Collison, 2001).

Fig. 2 - Gully head retreat cycle hypothesized by Collison (2001). Continuous lines in (a) represent planes of equal shear stress in gully head profile, with maximum (+) near the base (adapted from Collison, 2001). 
Outras combinações de processos incluem ofluting como motor do sapamento de uma camada sobrejacente e principal factor de recuo de cabeceiras (Vandekerckhove et al., 2000b), ou a formação de fracturas de tensão acima da cabeceira como processo promotor da formação e colapso de tubos (Harvey, 1982; Martín-Penela, 1994). Estes colapsos, em particular, têm sido descritos como eventos originadores de novas ravinas (Martín-Penela, 1994; Faulkner, 2006).

A complexidade resultante de todos os sub-processos acima referidos dificulta a consideração dos movimentos de massa no contexto do ravinamento em termos de um balanço entre resistência e tensão tangencial (como ocorre no cálculo do Factor de Segurança, cf. Morgan, $2005^{8}$ ). Não só a tensão relevante é frequentemente de natureza tênsil, por oposição a tangencial (Bull e Kirkby, 1997), como a configuração estrutural dos tubos dificilmente permitiria que o seu colapso fosse adequadamente considerado em termos de um só plano de rotura.

Enquanto mecanismo fundamental na evolução e no próprio surgimento de ravinas, os movimentos de massa têm recebido relativamente pouca importância na literatura, em benefício do escoamento (Bocco, 1991).

\section{PADRÕES DE DESENVOLVIMENTO}

\section{Ciclos e fases de evolução}

A noção de que as ravinas tendem a apresentar taxas de crescimento progressivamente menores, estabilizando com o tempo, está bem estabelecida (e.g. Poesen et al., 2003; 2006; Morgan, 2005). Wells et al. (1991), com base em observações em Madagáscar, propuseram um ciclo de desenvolvimento em cinco fases no qual, após uma fase de surgimento (1), uma fase de aprofundamento, regressão, e expansão lateral (2) é seguida da quase suspensão dos processos erosivos (3), revegetação, coluviação e suavização dos declives (4), e estabilização final, com as formas constituindo apenas concavidades planares na topografia (5). Este ciclo é em grande parte semelhante ao proposto por Ireland et al. (1939, cit. por Bocco, 1991) na Carolina do Sul (E.U.A.), sendo este último marcado pelo contraste na erodibilidade dos horizontes do solo. Caracteriza-se por uma fase inicial de entalhe, atravessando o horizonte A e parcialmente o B (1); uma fase intensa de entalhe e regressão da cabeceira, começando quando o horizonte $\mathrm{C}$ (facilmente erodível) é atingido (2); uma fase de reajustamento (3), em que movimentos de massa e enchimento coluvial suavizam o perfil do canal; e uma fase de estabilização (4), marcada pelo estabelecimento da vegetação.

A noção, comum a ambos os ciclos, de uma fase inicial de erosão intensa seguida de um período de estabilização progressiva, tem sido corroborada por diferentes estudos quantitativos da evolução de ravinas ao longo de vários anos, em que as dimensões são observadas como ajustando-se a funções exponenciais negativas do tempo desde o surgimento da forma (Rutherfurd et al., 1997; Sidorchuk, 1999; Nachtergaele et al., 2002a), do tipo:

$$
D=a\left(1-e^{-b T}\right)
$$

em que $D$ é a dimensão considerada (volume, comprimento, área), $T$ é o tempo desde o surgimento, e $a$ e $b$ são constantes, sendo $b$ denominada constante de decaimento. Nachtergaele

$8 F=\frac{\sigma}{\tau}$, em que $\sigma$ é a resistência ao corte do material, definida ao longo de um plano de rotura tangencial, e $\tau$ é a quantidade de tensão desenvolvida ao longo do mesmo plano. 
et al. (2002a) explicaram este padrão evolutivo com a diminuição do poder erosivo do escoamento, observando ao longo de 13 anos que a diminuição do produto entre área de drenagem e declive medido na cabeceira (proporcional à potência do escoamento) apresentou uma tendência igualmente exponencial. Ao longo do tempo, o escoamento deixará de possuir a energia necessária para remover o material proveniente de montante ou destacado por movimentos de massa, sendo a coluviação acentuada pela vegetação que entretanto se instala.

A noção de uma evolução exponencial assenta, porém, no pressuposto que os factores de controlo dos processos activos se comportam de forma constante ao longo do tempo. Em contraste, Nyssen et al. (2006) estudaram na Etiópia o padrão evolutivo de um conjunto de ravinas, observando uma tendência sigmoidal: a intensificação da degradação foi associada a mudanças no uso do solo (favorecendo o escoamento erosivo), e à ocorrência de um período relativamente seco (reduzindo a protecção conferida pela vegetação). Na Nova Zelândia, Parkner et al. (2006) estudaram a evolução de numerosas ravinas ao longo do período 1939-2003, definindo fases de expansão e inactividade abrangendo intervalos de vários anos, explicadas com modificações do coberto vegetal e a ocorrência de episódios de precipitação intensa. Vanwalleghem et al. (2005) estudaram a estratigrafia de uma antiga ravina entalhada em loess na Bélgica, definindo quatro ciclos de entalhe e enchimento estendendo-se ao longo de menos de cem anos.

Para além da assunção de um comportamento constante por parte dos factores de controlo (e.g. precipitação, uso do solo), a explicação da evolução das formas com recurso à área de drenagem e ao declive (Nachtergaele et al., 2002a) assenta em dois pressupostos que não se verificam necessariamente: (i) que a área de drenagem é necessariamente proporcional ao escoamento superficial, e (ii) que este controla fundamentalmente os processos erosivos. Em contraste com o primeiro pressuposto, Thomas et al. (2004) estudaram o comportamento hidrológico e o crescimento de uma ravina ao longo de 36 anos, observando que embora a área de drenagem tenha diminuído $8 \%$ durante esse período, a taxa de crescimento (em comprimento) diminuiu por mais do que um factor de 20. Esta disparidade levou à conclusão que a diminuição da taxa de crescimento observada resultou de uma diminuição significativa verificada no escoamento directo, atribuída à diminuição da frequência de episódios de precipitação intensa, ao aumento do coberto vegetal, e ao consequente aumento no escoamento de base. Como resultado, uma drenagem sub-superficial aumentada na base das paredes veio promover os movimentos de massa, e o escoamento superficial mostrou-se insuficiente para remover o material depositado (promovendo a suavização do declive nas paredes da ravina e a sua estabilização). Uma importante objecção aos dois pressupostos é a existência de ravinas que evoluem até ocuparem toda a sua área de drenagem inicial, podendo mesmo ultrapassar os seus limites (e.g. Wells et al., 1991; De Rose et al., 1998; Bacellar et al., 2005).

\section{Uma relação dinâmica entre processos: escoamento e movimentos de massa}

Ao longo do desenvolvimento de uma ravina, a importância relativa dos processos activos sofre variações. Betts et al. (2003) propuseram, para uma área da Nova Zelândia, que as ravinas incipientes evoluem essencialmente por processos de incisão fluvial. Porém, a partir de um limiar crítico - possivelmente controlado pela força tangencial e declive das paredes e pela profundidade do entalhe - começam a expandir-se lateralmente através de colapsos. Os movimentos de massa adquirem então uma importância crescente, acabando por tornar-se a principal fonte de sedimentos, e o escoamento passa a ter sobretudo a função de remover este material do canal, permitindo a sua expansão (e.g. Wells et al., 1991; Mor- 
gan, 2005). Blong et al. (1982) descreveram um padrão semelhante na Austrália. Estudando especificamente os processos laterais, observaram que embora estes só possam começar a agir depois da formação de um desnível suficiente, podem ser responsáveis por mais de metade do sedimento produzido. Martínez-Casanovas et al. (2003) observaram que, ao longo de vinte anos, a maioria do material gerado pelo sector de cabeceira de um grande sistema de ravinas teve origem em movimentos de massa nas paredes.

Estas observações implicam a transição entre uma primeira fase, em que a resposta do sistema à drenagem superficial é directa, para uma segunda fase em que esta resposta é condicionada pela disponibilização de material através de movimentos de massa. No seu estudo de uma ravina ao longo do período 1964-2000, Thomas et al. (2004), observaram que, anualmente, a eficiência erosiva do escoamento (razão entre a potência de escoamento necessária para mover o sedimento removido num dado período, e a potência possuída pelo escoamento verificado nesse período) não foi máxima no mês de maior volume de escoamento, mas subiu drasticamente no mês com maior frequência de movimentos de massa, atingindo o seu pico no mês a seguir (ainda um mês antes do escoamento máximo). De forma análoga, Hicks et al. (2003) observaram que, em média, metade dos sedimentos em suspensão removidos de uma sub-bacia fortemente ravinada na Nova Zelândia estão associados a eventos de precipitação com períodos de retorno inferiores a um ano, atestando o papel dos movimentos de massa como mecanismo de fornecimento de material facilmente mobilizável. Um exemplo extremo deste controlo é dado por Vandekerckhove et al. (2003) e Marzolff e Ries (2007): no Sudeste semi-árido de Espanha, uma ravina pode manter-se inactiva durante anos enquanto tubos alargam e fracturas de tensão se desenvolvem, evidenciando actividade considerável apenas quando um evento crítico despoleta colapsos na cabeceira e paredes.

A natureza episódica dos movimentos de massa e a sua resposta não linear à precipitação colocam em causa a definição do ravinamento como um processo inerentemente hídrico e comprometem a sua modelação com recurso a variáveis que traduzem apenas a erosividade do fluxo (Thomas et al., 2004). Collison (2001) propôs mesmo que, no caso do ravinamento, um modelo tradicional de erosão do tipo:

$$
\text { Erosão }=f(\text { erosividade, erodibilidade })
$$

deveria ser modificado para:

Erosão $=f($ resistência da cabeceira e paredes, tensão tangencial na cabeceira e paredes, erosividade, erodibilidade)

\section{Limiares geomórficos}

As interaç̧ões entre os processos que determinam o surgimento e crescimento de ravinas e as suas variáveis de controlo tornam evidente que o comportamento destas formas está sujeito a limiares, a partir dos quais se modifica. Schumm (1979) propôs o conceito de limiar geomórfico, dando como exemplo da sua aplicação o estudo do surgimento de ravinas em fundos de vale com recurso à área de drenagem e ao declive, de forma análoga aos limiares topográficos já referidos. O conceito foi definido como um limiar de estabilidade numa forma do relevo que é excedido por uma mudança intrínseca da própria forma, ou por uma mudança progressiva de uma variável externa. Em ordem a abranger toda a variabilidade observada na literatura, torna-se necessário alargar a definição original para incluir mudanças súbitas de variáveis externas. 
No que diz respeito ao ultrapassar de limiares extrínsecos, numerosos exemplos podem ser dados, frequentemente levando à intensificação da erosão: desflorestação (Gábris et al., 2003); mudança da cultura agrícola (e.g. conversão para cultivo da amendoeira, cf. Oostwoud Wijdenes et al., 2000; para vinha, cf. Martínez-Casanovas et al., 2004); eventos ou períodos extremos de precipitação (Dotterweich et al., 2003); construção de valas de drenagem ou estradas (Valcárcel et al., 2003) ou o aumento da densidade do gado ao longo do tempo, promovendo o pisoteio e a diminuição da vegetação (Boardman et al., 2003). Um exemplo de um limiar extrínseco ultrapassado com o resultado oposto é a florestação de uma área ravinada, levando à estabilização das formas sem que chegue a ocorrer enchimento (Vanwalleghem et al., 2003).

Limiares intrínsecos são atingidos, por exemplo, quando uma ravina em desenvolvimento atinge um material cuja resistência condiciona o seu crescimento e/ou orientação (e.g. Bacellar et al., 2005) ou, pelo contrário, acelera a degradação (e.g. Morgan e Mngomezulu, 2003). A transição entre uma fase dominada por processos fluviais e outra parcialmente controlada por movimentos de massa é outro exemplo.

\section{DISCUSSÃO}

A acção do escoamento é o factor por detrás da já referida concepção prevalecente da ravina como estágio intermédio num continuum de formas fluviais (Grissinger, 1996; Poesen et al., 2003, 2006). Esta noção foi reforçada pelos resultados obtidos por Nachtergaele et al. (2002b). Comparando seis conjuntos de dados de diferentes proveniências, os autores observaram que sulcos, ravinas (efémeras) e canais de (pequenos) rios podem ser descritos através de relações empíricas entre a largura do canal $(W$, em $\mathrm{m})$, e o caudal que registam $\left(Q, \mathrm{~m}^{3} \cdot \mathrm{s}^{-1}\right)$, do tipo:

$$
W=a Q^{b}
$$

sendo $a$ e $b$ constantes. O expoente $b$ variou, em média, entre 0.3 (sulcos), 0.4 (ravinas) e 0.5 (canais de pequenos rios).

A continuidade que estes resultados sugerem não é, porém, compatível com a variabilidade morfológica verificada entre as formas de maiores dimensões, frequentemente caracterizadas pelo alargamento e desenvolvimento de múltiplas cabeceiras. Exemplos são observáveis em Oostwoud Wijdenes e Bryan (2001), Morgan e Mngomezulu (2003), Marzolff e Ries (2007) ou Brooks et al. (2009). Adicionalmente, as ravinas ocorrem com frequência organizadas em sistemas hierárquicos que apenas raramente foram em si objecto de estudo (e.g. Donker e Damen, 1984), sendo mais habitual a consideração de formas individuais (ordem 1 ou 2), mesmo que neles integradas (e.g. Vandekerckhove et al., 2000b). Dois tipos fundamentais de sistemas de ravinas poderiam ser distinguidos utilizando como critério de diferenciação as características dos interflúvios entre canais individuais. Nos sistemas em rede (fig.3a), os canais e as respectivas cabeceiras estão relativamente mais afastados e são separados por porções não entalhadas da superfície topográfica envolvente, i.e. a superfície entre canais é a continuação da superfície exterior à rede (e.g. Donker e Damen, 1984; Martínez-Casanovas et al., 2004). Nos sistemas em complexo (fig. 3b), os canais são separados por interflúvios estreitos e de altitude inferior à da superfície topográfica exterior ao complexo, ou seja, os próprios interflúvios resultam da degradação da superfície topográfica original. Este é o caso das formas de grandes dimensões adequadamente denominadas "comple- 
xos de ravinas de flúvio-movimentação de massa" (fluvio-mass movement gully complexes no original) por Betts et al. (2003).
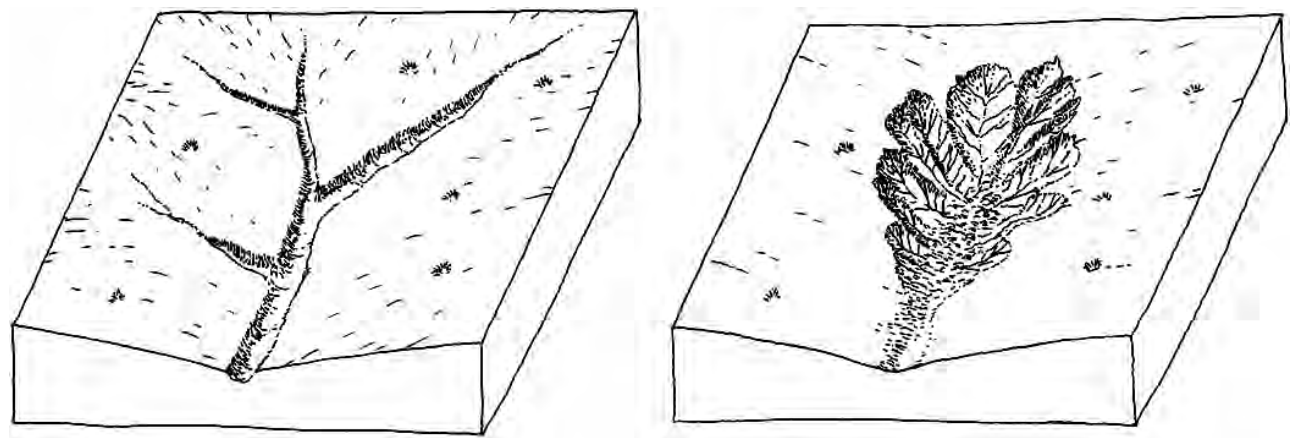

Fig.3 - Sistemas de ravinas. (a) em rede; (b) em complexo.

Fig.3 - Gully systems. (a) network; (b) complex.

Dada a incapacidade da concepção vigente de ravina para unificar a literatura, com inevitáveis consequências nas questões de investigação definidas e na coerência e utilidade do conhecimento resultante, torna-se necessário adoptar uma nova abordagem conceptual, encarando cada ravina ou sistema de ravinas, para uma dada escala temporal, como uma conjugação entre morfologia, processos (escoamento/movimentos de massa), e os factores de controlo destes últimos. As relações entre estes três elementos variarão ao longo do tempo, sendo a morfologia simultaneamente o resultado dos processos (Heede, 1970), e a sua causa. Face a este carácter dinâmico, o conceito de limiar geomórfico (Schumm, 1979) assume um papel estruturante: para cada ambiente de formação/evolução haverá limiares a partir dos quais se dão transições na natureza e importância dos processos activos (e.g. escoamento, movimentos de massa, tubulação), na dinâmica dominante (e.g. aprofundamento, alargamento, assoreamento, bifurcação), e na intensidade desta dinâmica. O conhecimento destes limiares (e.g. limiar de profundidade conducente à intensificação dos movimentos de massa) pode permitir definir fases características de evolução de uma forma objectiva, possibilitando a comparação dos resultados de estudos incidindo sobre formas em ambientes diferentes, mas fases de desenvolvimento (i.e. conjugações de morfologia e processos) semelhantes.

Ao contrário da abordagem fluvial que tem dominado a literatura, o enquadramento conceptual proposto permite abranger o ravinamento em toda a sua expressão, incluindo a dinâmica dos sistemas de formas (em rede e complexos). As redes só muito raramente foram consideradas (Donker e Damen, 1984), e os complexos têm sido alvo de estudos procurando quantificar o seu crescimento ao longo de um período e relacioná-lo com diferentes factores (e.g. DeRose et al., 1998; Martínez-Casasnovas et al., 2003), mas só raramente dando atenção às mudanças nas relações forma-processo que assistem ao seu surgimento a partir de formas incipientes (e.g. Betts et al, 2003).

Se o desenvolvimento de ravinas em rede é um elemento de ligação entre o ravinamento e a geomorfologia fluvial, os complexos adquirem particular significância na medida em que estabelecem a transição entre o ravinamento e a geomorfologia de badlands. Apesar dos trabalhos onde são descritas ravinas e áreas de badlands a ocorrer em simultâneo no mesmo local (e.g. Boardman et al., 2003; Harvey e Gutiérrez-Elorza, 2005), e dos bem estudados 
complexos de ravinas existentes em áreas de badlands na Península italiana (localmente designados calanchi, e.g. Alexander 1982; Moretti e Rodolfi, 2000), a importância destas formas intermédias parece não ter ainda sido alvo da devida atenção, existindo um hiato teórico entre os dois campos de estudos.

À luz da variabilidade descrita até este ponto, a maioria das definições de ravina analisadas afigura-se redutora, embora de diferentes formas (Quadro I): limitam a sua formação à acção do escoamento concentrado (e.g. Zachar, 1982; Ebisemiju e Ekiti, 1989), constrangemna à rede de drenagem (Hancock e Evans, 2006), às vertentes (Kirkby e Bracken, 2009), assumem morfologias que não se verificam necessariamente (e.g. seç̧ão em V, cf. Bull e Kirkby, 1997), ou a inexistência prévia de um canal bem definido (Schumm et al., 1984, cit. por DeRose et al., 1998). Embora a definição de Morgan (2005) seja a mais coerente, assenta em parte na morfologia das paredes (declivosas) e não na dinâmica erosiva que lhe está directamente na origem.

De forma a construir uma definição coerente, adaptaram-se as propostas de Schumm et al. (1984) e Morgan (2005) e tornou-se explícita a natureza mista (fluvial/gravitacional) do ravinamento, já salientada por Bocco (1991) e por Collison (2001). Considerou-se assim que uma ravina poderá ser genericamente definida como "um canal relativamente fundo, instável e em processo de erosão que evolui através da conjugação entre um escoamento efémero em contextos de alimentação em precipitação e movimentos de massa ${ }^{9}$." O ravinamento é assim implicitamente definido como o fenómeno do surgimento e evolução destes canais, por oposição à definição vigente (vd. 1.), assente em exclusivo na acção do escoamento ao dar origem a canais relativamente incipientes.

Do ponto de vista da aplicação, o enquadramento proposto permite ajustar as medidas de controlo e prevenção à dinâmica presente e futura das formas no terreno. Vários exemplos podem ser citados: Morgan e Mngomezulu (2005) observaram na Suazilândia que algumas ravinas resultavam fundamentalmente do escoamento Hortoniano, enquanto outras pareciam estar numa fase mais avançada, sendo controladas pela drenagem sub-superficial na cabeceira. Nesta fase, medidas que favorecem a infiltração são prejudiciais: Nir e Klein (1974) observaram numa área de estudo em Israel que a adopção da lavra segundo as curvas de nível reduziu o escoamento superficial, mas promoveu o escoamento sub-superficial, contribuindo para a tubulação e para a formação e crescimento de ravinas. Betts et al. (2003) enfatizaram a importância do conhecimento das fases de evolução, salientando a inutilidade de levar a cabo programas de plantação em ravinas jovens em expansão intensa através de movimentos de massa, e o desperdício de o fazer com formas em estabilização. A mesma ineficiência decorre da aplicação de estruturas de controlo de cabeceiras em ravinas com forte dinâmica lateral (Blong et al., 1982).

Por fim, foi definido um conjunto de cinco questões para investigação à luz do enquadramento conceptual proposto. Para diferentes contextos ambientais, e ao longo do desenvolvimento de uma dada forma:

(1) Como variam as contribuições dos diferentes processos (e.g. escoamento, movimentos de massa, tubulação) para a resposta erosiva?

(2) Que factores controlam a morfologia e em que medida a sua importância muda ao longo do tempo (e.g. quais os factores que definem a ocorrência de uma forma de "tipo fluvial" por oposição a uma forma alargada com múltiplas cabeceiras)?

9 Esta definição genérica é compatível com outras assumidamente parciais (e.g. ravina efémera), mas cujo valor prático é inegável. 
(3) Podem ser delimitadas fases de desenvolvimento de base quantitativa, por oposição às fases qualitativas postuladas no passado (e.g. Ireland et al., 1939; Wells et al., 1991)?

(4) Que factores controlam a transição entre uma forma individual e um sistema em rede ou complexo?

(5) Que dinâmicas específicas apresentam os sistemas de ravinas e em que medida estas são controladas por diferentes factores (e.g. que factores determinam a estabilização de um complexo de ravinas, ou a sua expansão e coalescência com formas semelhantes até à formação de uma badland)?

\section{O ESTUDO DO RAVINAMENTO EM PORTUGAL}

Embora frequentemente referido, tanto na literatura de âmbito geográfico mais geral como na mais centrada na geomorfologia ou na erosão do solo, o ravinamento tem sido, em Portugal, tema principal de escassos trabalhos.

Rebelo (1982) e Rebelo et al. (1986) descreveram o fenómeno em três locais distintos, no interior do perímetro urbano de Coimbra e nos arredores, observando a importância de diferentes factores naturais e antrópicos, e levantando a questão da definição de ravina e dos limiares associados a formas de diferentes dimensões.

Alguns anos mais tarde, a colaboração possibilitada pelo projecto MEDALUS (Mediterranean Desertification and Land Use), decorrendo entre 1991 e 1998 e abrangendo instituições de oito países da União Europeia (cf. Roxo e Casimiro, 1999), esteve na base de uma grande parte da bibliografia actualmente existente, centrada em áreas de trabalho nos concelhos de Mértola e Bragança. Estes trabalhos são de seguida revistos.

Vandaele et al. (1996) e Vandekerckhove et al. (1998, 2000a) determinaram limiares topográficos para o surgimento de ravinas incipientes em ambas as áreas de trabalho, comparando-os com os obtidos em outros contextos ambientais. Posteriormente, Oostwoud Wijdenes et al. (1999) integraram os resultados de levantamentos de campo realizados por Vandekerckhove et al. (1998) com dados de uma área de estudo no Sudeste de Espanha, com vista ao estudo das relações entre a morfologia das cabeceiras de ravinas, o seu contexto ambiental, e o grau de desenvolvimento.

Vandaele et al. (1997) estimaram taxas de erosão em ravinas incipientes a partir de fotografias aéreas (1970-1985) para a área de Mértola. A comparação dos valores com dados publicados, obtidos em parcelas experimentais na estação de Vale Formoso, permitiu concluir que o ravinamento (efémero) esteve, durante o período considerado, associado a taxas entre 4,5 e 5,2 vezes superiores às resultantes do escoamento laminar e em sulcos. Poesen et al. (1996) compararam o mesmo conjunto de dados com resultados obtidos em áreas experimentais na Bélgica e em Espanha, associando a grande importância relativa do ravinamento efémero nos dois países ibéricos ao elevado conteúdo em fragmentos de rocha no solo, impedindo a erosão pelo escoamento laminar, mas não a sua concentração e acção erosiva a jusante (onde a ausência de carga transportada contribui para a capacidade erosiva).

A área de Mértola foi também utilizada por Nachtergaele et al. (2001) para testar o modelo EGEM (Ephemeral Gully Erosion Model; Woodward, 1999), e por Nachtergaele et al. (2002b) para obter dados morfométricos de ravinas efémeras, depois combinados com outros no estudo da relação entre caudal e largura para canais de diferentes dimensões. 
Fora do contexto do projecto MEDALUS, Pedrosa et al. (2001) estudaram o desenvolvimento de quatro ravinas amostrais na Serra do Marão, em diferentes contextos topográficos e litológicos. A monitorização das formas aproximadamente ao longo de nove meses permitiu observar que não existe relação directa entre precipitação e quantidade de material erodido, evidenciando o controlo exercido por processos que não o escoamento. Estes foram identificados pelos autores como movimentos de massa resultantes de ciclos de congelamento/ fusão da água no solo e, em menor grau, a acção de escavamento realizada por insectos.

Martins (2009) centrou-se mais recentemente na geomorfologia e na dinâmica quaternária da depressão Régua-Chaves-Verin, articulando-as com o ravinamento através da construção de um índice de risco e da respectiva cartografia. Roxo e Calvo-Cases (2009) abordaram o fenómeno no contexto do abandono do solo agrícola em Mértola. Com recurso a uma série temporal de imagens Landsat (1976-2005), descreveram um ciclo natural de incisão e estabilização de ravinas, com duração variável consoante a posição topográfica dos entalhes (fundo de vale/vertentes). Este ciclo inicia-se com a conversão de áreas agrícolas em pastagens, sendo a estabilização eventualmente atingida com a recuperação do coberto vegetal e, nas vertentes, com o desenvolvimento de crostas biológicas e o aumento relativo da granulometria do material. Por fim, Bergonse e Reis (2010) caracterizaram os grandes padrões de ravinamento numa área de âmbito regional na bacia do Baixo Tejo. As formas observadas estenderam-se desde canais recentes, activos em estradas florestais, até grandes complexos parcialmente activos abrangendo milhares de metros quadrados. Esta grande variabilidade deixou clara a existência de formas com âmbitos temporais muito distintos, e a necessidade de adoptar diferentes metodologias em futuros estudos de pormenor, ilustrando bem a complexidade morfológica e processual que o ravinamento pode assumir.

\section{CONCLUSÕES}

A revisão bibliográfica realizada deixou claro que as diferentes definições de ravina, bem como a noção prevalecente destas formas como um estágio intermédio entre canais fluviais de diferentes dimensões, não abrangem a variedade de formas e processos existente, perpetuando uma representação inadequada do ravinamento como fenómeno essencialmente hídrico. Em ordem a promover a coerência teórica desde campo de estudos, e à semelhança de trabalhos anteriormente publicados, considerou-se crítico o reconhecimento definitivo da importância dos movimentos de massa.

Foi proposta uma definição genérica de ravina, bem como a concepção destas formas como conjugações, dinâmicas ao longo do tempo, entre morfologia, processos e as variáveis de controlo destes, constituindo o conceito de limiar geomórfico uma importante ferramenta teórica para o seu estudo. Esta abordagem dinâmica pode permitir ajustar medidas de prevenção e controlo aos processos relevantes em cada caso, por oposição à frequente ineficácia de medidas assentes no pressuposto de um controlo universal por parte do escoamento superficial.

De acordo com o enquadramento conceptual proposto, considerou-se importante que seja dada mais atenção ao surgimento e evolução dos sistemas de ravinas (em rede e em complexo) cuja evolução, com mais frequência do que a das formas isoladas, estabelece as ligações entre os campos teóricos do ravinamento, da geomorfologia fluvial e da geomorfologia de badlands. 


\section{BIBLIOGRAFIA}

Alexander D (1982) Difference between "calanchi" and "biancane" badlands in Italy. In Bryan R, Yair A (Eds.) Badland Geomorphology and Piping. GeoBooks: 71-87.

Bacellar L, Coelho Netto A, Lacerda W (2005) Controlling factors of gullying in the Maracujá catchment, Southeastern Brazil. Earth Surface Processes and Landforms, 30: 1369-1385 .

Bergonse R, Reis E (2010) Definição e caracterização de padrões de ravinamento à escala regional: o caso da bacia do Tejo. In Bateira C, Soares L, Gomes A, Chaminé H (eds.) Livro de Actas do V Congresso Nacional de Geomorfologia. Associação Portuguesa de Geomorfólogos: 237-243.

Betts H D, Trustrum N A, De Rose R C (2003) Geomorphic changes in a complex gully system measured from sequential digital elevation models, and implications for management. Earth Surface Processes and Landforms, 28: 1043-1058.

Billi P, Dramis F (2003) Geomorphological investigation on gully erosion in the Rift Valley and the northern highlands of Ethiopia. Catena, 50: $353-368$.

Blong R J, Graham O P, Veness J A (1982) The role of sidewall processes in gully development; some N.S.W. examples. Earth Surface Processes and Landforms 7: 381-385.

Boardman J, Parsons A J, Holland R, Holmes P J, Washington R (2003) Development of badlands and gullies in the Sneeuberg, Great Karoo, South Africa. Catena, 50: 165-184.

Boardman J, Poesen A J (2006) - Soil Erosion in Europe: Major Processes, Causes and Consequences. In Boardman, J., Poesen, J. (Eds.) Soil Erosion in Europe. John Wiley and Sons: 479-487.

Bocco G (1991) Gully erosion: processes and models. Progress in Physical Geography 15 (4): 392-406.

Bradford J M, Piest R F (1980) - Erosional development of valley-bottom gullies in the upper midwestern United States. In Coates D R, Vitek J D (eds.) Thresholds in Geomorphology. George Allen \& Unwin: 75-101.

Brice J B (1966) - Erosion and deposition in the loess-mantled Great Plains, Medecine Creek drainage basin, Nebraska. U.S.Geological Survey Professional Paper 352H: 235-339.

Brooks A P; Shellberg J G, Knight J, Spencer J (2009) Alluvial gully erosion: an example from the Mitchell fluvial megafan, Queensland, Australia. Earth Surface Processes and Landforms, 34: 1951-1969.

Bryan R (2000) Soil erodibility and processes of water erosion on hillslope. Geomorphology, 32: 385-415.

Bull L J, Kirkby M J (1997) Gully processes and modelling. Progress in Physical Geography 21 (3): 354-374.

Burkard M B, Kostachuck R A (1997) Patterns and controls of gully growth along the shoreline of lake Huron. Earth Surface Processes and Landforms, 22: 901-911.

Capra A, Mazzara L M, Scicolone B (2005) Application of the EGEM model to predict ephemeral gully erosion in Sicily, Italy. Catena, 59: 133146.

Casalí J, López J J, Giráldez J V (1999a) Ephemeral gully erosion in southern Navarra (Spain). Catena, 36: 65-84.

Casali J, Laburu A, López J J, García R (1999b) Digital terrain modelling of drainage channel evolution. Journal of Agricultural Engineering Research, 74: 421-426.

Collison A J C (2001) The cycle of instability: stress release and fissure flow as controls on gully head retreat. Hydrological Processes 15: 3-12.

Crouch R J, Blong R J (1989) Gully sidewall classification: methods and applications. Z.Geomorph, 33 (3): 291-305.

De Ploey J (1974) Mechanical properties of hillslopes and their relation to gullying in Central semi-arid Tunisia. Z. Geomorph. Suppl. Bd., 21: 177-190.

De Rose R C, Gomez B, Marden M, Trustrum N A (1998) Gully erosion in Mangatu Forest, New Zealand, estimated from digital elevation models. Earth Surface Processes and Landforms, 23: 1045-1053.

De Santisteban L M, Casalí J, López J J, Giráldez J V, Poesen J, Nachtergaele J (2005) Exploring the role of topography in small channel erosion. Earth Surface Processes and Landforms, 30: 591-599. 
Desir G, Marín C, Gutiérrez M (2009) Influencia de los processos de sofusión (Piping) en la evolución del modelado. Bardenas Reales (Navarra). In Diaz A R, Serrato F B, Sarria F A, Lopez Bermúdez F (coords.) - Advances in Studies on Desertification: Contributions to the International Conference on Desertification in Memory of Professor John B. Thornes. Publicaciones de la Universidad de Múrcia: 223-226.

Desmet P J, Poesen J, Govers G, Vandaele K (1999) Importance of slope gradient and contributing area for optimal prediction of the initiation and trajectory of ephemeral gullies. Catena, 37: 377-392.

Donker N H W, Damen M C J (1984) Gully system development and an assessment of gully initiation risk in Miocene deposits near Daroca - Spain. Z.Geomorph.Suppl.Bb., 49: 37-50.

Dotterweich M, Schmitt A, Schmidtschen G, Bork H (2003) Quantifying historical gully. London.

Ebisemiju F, Ekiti A (1989) A morphometric approach to gully analysis. Z.Geomorph., 33 (3):

FAO (Food and Agriculture Organization) (1965) Soil Erosion by Water. Some Measures for its Control on Cultivated Lands. FAO Agricultural Paper $n^{\circ} 81$. Rome.

Faulkner H (2006) Piping hazard on collapsible and dispersive soils in Europe. In Boardman J, Poesen J (eds.) Soil Erosion in Europe. John Wiley and Sons: 537-562.

Foster G R, Flanagan D C, Nearing M A, Lane L J, Risse L M, Finker S C (1995) Chapter 11. Hillslope Erosion Component. In NSERL Water Erosion Prediction Project (WEPP). Technical Documentation. NSERL Report No.10. National Soil Erosion Research Laboratory. West Lafayette, IN. http://www.ars. usda.gov/Research/docs.htm?docid=18073) [Extraído a 29 de Junho de 2009].

Gábris G, Kertész Á, Zámbó L (2003) Land use change and gully formation over the last 200 years in a hilly catchment. Catena, 50: 151-164 .

Gallart F, Solé A, Puigdefàbregas J, Lázaro R (2002) Badland systems in the Mediterranean. In Bull L J, Kirkby M J (eds.) Dryland Rivers: Hydrology and Geomorphology of Semi-Arid Channels. John Wiley and Sons.

Govers G, Giménez R, Van Oost K (2007) Rill erosion: exploring the relationship between ex- periments, modelling and field observations. Earth-Science Reviews, 84: 87-102.

Goudie A S (2004) Arroyo. In Goudie A S (ed.) Encyclopedia of Geomorphology. Routledge: 32-34.

Gregory K J, Walling D E (1973) Drainage Basin Form and Process. Edward Arnold,

Grissinger E (1996) Rill and gullies erosion. In Agassi M (ed.) Soil Erosion, Conservation and Rehabilitation. CRC Press: 153-168.

Hancock G R, Evans K G (2006) Gully position, characteristics and geomorphic thresholds in an undisturbed catchment in northern Australia. Hydrological Processes, 20: 2935$-2951$.

Harvey A (1982) The role of piping in the development of badlands and gully systems in southeast Spain. In Bryan R, Yair A (eds.) Badland Geomorphology and Piping. GeoBooks: 317335.

Harvey A, Gutiérrez-Elorza M (2005) Repeated patterns of Quaternary discontinuous gullying at El Tormillo, Ebro Basin, Spain. In Garcia C, Batalla R J (eds.) Catchment Dynamics and Rivers Processes: Mediterranean and Other Climate Regions. Elsevier: 53-67.

Hauge C (1977) Soil erosion definitions. California Geology, 30: 202-203.

Heede B (1970) Morphology of gullies in the Colorado Rocky Mountains. Bull. of the Internat. Assoc. of Scientific Hydrology, XV (2): 79-89.

Hicks D M, Gomez B, Trustrum N A (2000) Erosion thresholds and suspended sediment yields, Waipaoa River Basin, New Zealand. Water Resources Research, 36 (4): 1129-1142.

Horton R E (1945) Erosional development of streams and their drainage basins ; hydrophysical approach to quantitative morphology. Geological Society of America Bulletin 56: 275-370.

Imeson A C, Kwaad F J (1980) Gully types and gully prediction. KNAG Geografisch Tijdschrift XIV (5): 430-441.

Ireland H A, Sharpe C F, Eagle D H (1939) Principles of Gully Erosion in the Piedmont of South Carolina. U.S. Department of Agriculture, Technical Bulletin 633.

Jones J A A (1987) The initiation of natural drainage networks. Progress in Physical Geography, 11: 207-245.

Kakembo V, Xanga W W, Rowntree K (2009) Topographic thresholds in gully development 
on the hillslopes of communal areas in Ngqushwa Local Municipality, Eastern Cape, South Africa. Geomorphology, 110: 188-194.

Kirkby M J, Bracken L J (2009) Gully processes and gully dynamics. Earth Surface Processes and Landforms, 34: 1841-1851.

Knapen A, Poesen J, Govers G, Gyssels G, Nachtergaele J (2007) Resistance of soils to concentrated flow erosion: A review. Earth-Science Reviews, 80: 75-109.

Leopold L B, Wolman M G, Miller J P (1964) Fluvial Processes in Geomorphology. W.H. Freeman and Company.

Lesschen J P, Cameraat L H, Nieman T (2008) Erosion and terrace failure due to agricultural land abandonment in a semi-arid environment. Earth Surface Processes and Landforms, 33: 1574-1584.

Martínez-Casasnovas J A, Antón-Fernández C, Ramos M C (2003) Sediment production in large gullies of the Mediterranean area (NE Spain) from high-resolution digital elevation models and geographical information systems analysis. Earth Surface Processes and Landforms, 28: 443-456.

Martínez-Casasnovas J A, Ramos M C, Poesen J (2004) Assessment of sidewall erosion in large gullies using multi-temporal DEMs and logistic regression analysis. Geomorphology, 58: 305-321.

Martín-Penela A J (1994) Pipe and gully systems development in the Almanzora Basin (Southeast Spain). Z.Geomorph., 38 (2): 207-222.

Martins B (2009) A Depressão de Régua-Chaves-Verin - Contributo para a Análise do Risco de Ravinamento. Dissertação de Doutoramento, Coimbra.

Marzolff I, Ries J (2007) Gully erosion monitoring in semi-arid landscapes. Z.Geomorph., 51 (4): 405-425.

Menéndez-Duarte R, Marquíne J, Fernández-Menéndez S, Santos R (2007) Incised channels and gully erosion in Northern Iberian Peninsula: controls and geomorphic setting. Catena, 71 : 267-278.

Moretti S, Rodolfi G (2000) A typical "calanchi" landscape on the Eastern Apennine margin (Atri, Central Italy): geomorphological features and evolution. Catena 40: 217-228.

Morgan R C P (2005) Soil Erosion and Conservation. Blackwell Publishing.
Morgan R P C, Mngomezulu D (2003) Threshold conditions for initiation of valley-side gullies in the Middle Veld of Swaziland. Catena, 50: 401-414.

Nachtergaele J, Poesen J, Vandekerckhove L, Oostwoud Wijdenes D, Roxo M (2001) Testing the ephemeral gully erosion model (EGEM) for two Mediterranean environments. Earth Surface Processes and Landforms, 26: 17-30.

Nachtergaele J, Poesen J, Oostwoud Wijdenes D, Vandekerckhove L (2002a) Medium-term evolution of a gully developed in a loess-derived soil. Geomorphology, 46: 223-239.

Nachtergaele J, Poesen J, Sidorchuk A, Torri D (2002b) Prediction of concentrated flow width in ephemeral gully channels. Hydrological Processes, 16: 1935-1953.

Nearing M A, Norton L D, Bulgakov D A, Larionov G A, West L T, Dontsova K M (1997) Hydraulics and erosion in eroding rills. Water Resources Research, 33 (4): 865-876

Nir D, Klein M (1974) Gully erosion induced in land use in a semi-arid terrain (Nahal Shikma, Israel). Z.Geomorph. N.F. Suppl. Bd, 21: 191-201.

Nyssen J, Poesen J, Veyret-Picot M, Moeyersons J, Haile M, Deckers J, Dewit J, Naudts J, Teka K, Govers G (2006) Assessment of gully erosion rates through interviews and measurements: a case study from northern Ethiopia. Earth Surface Processes and Landforms, 31: 167-185.

Oostwoud Wijdenes D, Poesen J, Vandekerckhove L, Nachtergaele J, De Baerdemaeker J (1999) Gully-head morphology and implications for gully development on abandoned fields in a semi-arid environment, Sierra de Gata, Southeast Spain. Earth Surface Processes and Landforms, 24: 585-603.

Oostwoud Wijdenes D. Poesen J, Vandekerckhove L, Guesquierem M (2000) Spatial distribution of gully head activity and sediment supply along an ephemeral channel in a Mediterranean environment. Catena, 39: 147-167.

Oostwoud Wijdenes D, Bryan R (2001) Gully-head erosion processes on a semi-arid valley floor in Kenya: a case study into temporal variation and sediment budgeting. Earth Surface Processes and Landforms, 26: 911-933.

Panin A V, Fuzeina J N, Belyaev V R (2009) Longterm development of Holocene and Pleistocene gullies in the Provta River Basin, Central Russia. Geomorphology, 108: 71-91. 
Parkner T, Page M, Marutani T, Trustrum N (2006) Development and controlling factors of gullies and gully complexes. East Coast, New Zealand. Earth Surface Processes and Landforms, 31: 187-199.

Pedrosa A, Bateira C, Soares L, Silvério M (2001) Metodologia para o estudo dos ravinamentos. In Metodologias de Estudos de Processos de Erosão do Solo. Universidade do Porto: 8598.

Poesen J (1993) Gully typology and gully control measures in the European loess belt. In,

Wicherek S (ed.) Farm Land Erosion in Temperate Plains Environment and Hills. Elsevier, Amsterdam: 221-239.

Poesen J, Vandaele K, Van Wesemael B (1996) Contribution of gully erosion to sediment production on cultivated lands and rangelands. In Erosion and Sediment Yield: Global and Regional Perspectives. Proceedings of the Exeter Symposium, July. IAHS Publication $\mathrm{n}^{\mathrm{o}} 236$.

Poesen J, Nachtergaele J, Verstraeten G, Valentin C (2003) Gully erosion and environmental change: importance and research needs. Catena, 50: 91-133.

Poesen J, Vanwalleghem T, de Vente J, Knapen A, Verstraeten G, Martínez-Casasnovas J (2006) Gully erosion in Europe. In Boardman J, Poesen J (eds.) Soil Erosion in Europe. John Wiley and Sons: 515-536.

Rauws G, Govers G (1988) Hydraulic and soil mechanical aspects of rill generation on agricultural soils. The Journal of Soil Science, 39: 111-124.

Rebelo F (1982) Considerações metodológicas sobre o estudo dos ravinamentos. Livro de Comunicações, II Colóquio Ibérico de Geografia, Lisboa, 1980, Vol 1: 339-350.

Rebelo F, Cunha L, Rochette Cordeiro A M (1986) Sobre a origem e a evolução actual dos ravinamentos em calcários margosos na área de Condeixa. Actas do IV Colóquio Ibérico de Geografia, Coimbra: 875-882.

Roxo M J, Casimiro P C (1999) MEDALUS: Mediterranean Desertification and Land Use.

Estudos sobre Desertificação no Baixo Alentejo Interior - Concelho de Mértola. GeoInova Revista do Departamento de Geografia e Planeamento Regional, 0: 6-29.

Roxo M J, Calvo-Cases A (2009) Analysing the factors affecting gully development and their re- lationships with land-use changes in the east Alentejo (Portugal). In Diaz A R, Serrato F B, Sarria F A, Lopez Bermúdez F (coords.) Advances in Studies on Desertification: Contributions to the International Conference on Desertification in Memory of Professor John B. Thornes. Publicaciones de la Universidad de Murcia: 717-720.

Rutherfurd I D, Prosser I P, Davis J (1997) Simple approaches to predicting rates and extent of gully development. In Wang S S Y, Langendoen E J, Shields J R (eds.) Proceedings of the Conference on Management of Landscapes Disturbed by Channel Incision. The University of Mississsipi, Oxford, Mississipi: 1125-1130.

Schumm S A (1979) Geomorphic Thresholds: the concept and its applications. Transactions of the Institute of British Geographers, New Series, 4: 484-515.

Schumm S A, Harvey M D, Watson C C (1984) Incised Channels. Water Resources Publications, Littleton, Colorado.

Seeger M, Marzolff I, Ries J B (2009) Identification of gully-development processes in semiarid NE Spain. Z.Geomorph. N.F., 53 (4): 417-431.

Sidorchuk A (1999) Dynamic and static models of gully erosion. Catena, 37: 401-414.

Soil Science Society of America (2001) Glossary of Soil Science Terms. Soil Science Society of America, Madison, WI. https://www.soils. org/publications/soils-glossary [Acedido em 5 de Junho de 2009].

Souchère V, Cerdan $\mathrm{O}$, Ludwing $\mathrm{B}$, Le Bisonnais $\mathrm{Y}$, Couturier A, Papy F (2003) Modelling ephemeral gully erosion in small cultivated catchments. Catena, 50: 489-505.

Thomas J T, Iverson N R, Burkart M R, Kramer L A (2004) Long-term growth of a valley-bottom gully, western Iowa. Earth Surface Processes and Landforms, 29: 995-1009.

Thomas J T, Iverson N R, Burkart M R (2009) Bankcollapse processes in a valley bottom gully, western Iowa. Earth Surface Processes and Landforms, 34: 109-122.

Toy T, Foster G, Renard K (2002) Soil Erosion. Processes, Measurement and Control. Wiley.

Valcárcel M, Taboada M T, Paz A, Dafonte J (2003) Ephemeral gully erosion in northwestern Spain. Catena, 50: 199-216. 
Vandaele K, Poesen J, Govers G, van Wesemael B (1996) Geomorphic threshold conditions for ephemeral gully incision. Geomorphology, 16: 161-173.

Vandaele K, Poesen J, Marques da Silva J R, Govers G, Desmet P (1997) Assessment of factors controlling ephemeral gully erosion in Southern Portugal and Central Belgium using aerial photographs. Z.Geomorph.N.F. 41 (3): 273287.

Vandekerkhove L, Poesen J, Oostwoud Wijdenes D, Figueiredo T de (1998) Topographical thresholds for ephemeral gully initiation in intensively cultivated areas of the Mediterranean. Catena, 33: 271-292.

Vandekerkhove L, Poesen J, Oostwoud Wijdenes D, Nachtergaele J, Kosmas C, Roxo M J, Figueiredo T de (2000a) Thresholds for gully initiation and sedimentation in Mediterraean Europe. Earth Surface Processes and Landforms, 2: 1201-1220.

Vandekerkhove L, Poesen J, Oostwoud Wijdenes D, Gyssels G, Beuselink L, de Luna E (2000b) Characteristics and controlling factors of bank gullies in two semi-arid Mediterranean environments. Geomorphology, 33: 37-58.

Vandekerkhove L, Poesen J, Govers G (2003) Medium-term gully headcut retreat rates in Southeast Spain determined from aerial photographs and ground measurements. Catena, 50: 329-352.

Vanwalleghem T, Van Den Eeckhaut M. Poesen J, Deckers J, Nachtergaele J, Van Oost K, Slenters C (2003) Characteristics and controlling factores of old gullies under forest in a temperate humid climate: a case study from the Meerdal Forest (Central Belgium). Geomorphology, 56: 15-29.

Vanwalleghem T, Bork H R, Poesen J, Schmidtchen G, Dotterweich M, Nachtergaele J, Bork H, Deckers J, Brüsch B, Bungeneers J, De Bie M (2005) Rapid development and infilling of a buried gully under cropland, central Belgium. Catena, 63: 221-243.

Wainwright J, Thornes J (2004) Environmental Issues in the Mediterranean - Processes and Perspectives From the Past and Present. Rouledge.

Wasson R J, Caitcheon G, Murray A S, Mcculloch M, Quade J (2002) Sourcing sediment using multiple tracers in the catchment of lake Argyle, Northwestern Australia. Environmental Management, 29: 634-646.

Wells N, Andriamihaja B, Rakotovololona H F (1991) Patterns of development of lavaka, Madagascar's unusual gullies. Earth Surface Processes and Landforms, 16: 189-206.

Woodward D E (1999) Method to predict cropland ephemeral gully erosion. Catena, 37: 393399.

Zachar D (1982) Soil Erosion. Developments in Soil Science 10. Elsevier.

Zucca C, Canu A, Della Peruta R (2006) Effects of land use and landscape on spatial distribution and morphological features of gullies in an agropastoral area in Sardinia (Italy). Catena, 68: 87-95. 